Article

\title{
Urban Connective Action: The Case of Events Hosted in Public Space
}

\author{
David McGillivray *, Severin Guillard and Emma Reid \\ School of Business and Creative Industries, University of the West of Scotland, Paisley, PA1 2BE, UK; \\ E-Mails: david.mcgillivray@uws.ac.uk (D.M.), severin.guillard@uws.ac.uk (S.G.), emma.reid@uws.ac.uk (E.M.) \\ * Corresponding author
}

Submitted: 29 June 2020 | Accepted: 28 August 2020 | Published: 15 December 2020

\begin{abstract}
In the past decade, significant transformations have influenced the governance of urban public spaces. There has also been a growth in new public spheres associated with digital media networks, informing and influencing the production and regulation of urban space. In this article, we explore the role of digital and social media as a form of connective action supporting public campaigns about the privatisation and erosion of public space in the Scottish city of Edinburgh. We draw on analysis of Twitter data, interviews and observations of offline events to illustrate how a broad coalition of actors utilise online and offline tactics to contest the takeover of public space, confirming that that the virtual and the physical are not parallel realms but continuously intersecting social realities. Finally, we reflect on the extent to which digital media-enabled connective action can influence the orientation of urban controversies debates and lead to material change in the way urban public space is managed and regulated.
\end{abstract}

\section{Keywords}

connective action; Edinburgh; festivals and events; public space; urban controversy

Issue

This article is part of the issue "Digital Geographies and the City" edited by Wen Lin (Newcastle University, UK).

(C) 2020 by the authors; licensee Cogitatio (Lisbon, Portugal). This article is licensed under a Creative Commons Attribution 4.0 International License (CC BY).

\section{Introduction}

In January 2020, a public meeting was organised at Edinburgh Central Hall titled City for Sale? The Commodification of Edinburgh's Public Spaces. Initiated and organised by the civic heritage organisation, The Cockburn Association, this event focused on a new threat to the city's public spaces: Their closing off for extended periods of time to host major commercial events. Attended by 850 people, including several wellknown public figures (a journalist from the national television channel BBC Scotland, and a Member of the Scottish Parliament from the Green Party), this event reflected significant concern from Edinburgh's residents about the use and management of public space in the city. The event focused on public space and its value, the role of festivals and events in the city, and the opportunity available to residents to influence decision-making in the way their public spaces are used. The meeting was also the culmination of months, if not years, of discussion and debate about the relationship between the Festival City (as it is often titled) and its environs. These discussions have taken place in physical meetings and gatherings, but more recently they have played out in the media and on digital and social media platforms. The Edinburgh case is an emblematic example of how, in the context of contemporary cities, online and offline collective action can unite to influence the way urban public space is managed and regulated.

In the past few decades, urban researchers have highlighted how the management and design of urban public space has become influenced by many, often contradictory, demands. These range from exposure to a neoliberal agenda that encourages the local state to commercialise its public and common good assets for economic return (Smith, 2016), to increased calls for the inclusion of local communities in the design of their urban environments (Aelbrecht, 2019). In the last two decades, the 
emergence of so-called new public spheres (Papacharissi, 2002), associated with digital media networks, has introduced another layer to the urban debate. By creating a new 'skin' for cities (Rabari \& Storper, 2015), the digital sphere is informing and influencing the production and regulation of urban space, especially when it comes to the mobilisation of citizens in the form of campaigns and protests (Arora, 2015; Molnar, 2014; Schäfer, 2015).

In this article, we explore the extent to which digital and social media platforms enable the expression of public concerns over the management, use and design of public space in the context of the growing festivalisation of cities (Richards \& Palmer, 2010). It connects two areas of debate: The reconfiguration of the relationship between physical and virtual spaces, and the changing modes of production of urban public space, torn between new attempts to open them to diverse types of citizens and their promotion as assets in a neoliberal context. Empirically, we focus on the Scottish city of Edinburgh, which has long been considered an international festival city (Jamieson, 2014). Drawing on the urban controversies created over the use of the city's principal public spaces for festival and event-related activities, we address the following research question: How do online and offline politics operate in relation to discussions about the value of hosting festivals and events in urban civic public space, and with what effects?

Structurally, we begin by discussing the concept of 'connective action,' exploring how narratives of digitalisation can reframe local activism by providing new means to contest the management and use of public spaces. We then focus on how these digitally mediated processes interact with existing trends in the management and use of public space, especially where they reinforce and contest already existing processes of privatisation, commodification and festivalisation. We detail our single case study, before presenting empirical evidence on the extent to which offline and online politics were successful in initiating change in the governance of urban public space in Edinburgh.

\section{Digital Deliberation and the Public Sphere: Connective Action in Operation}

There is growing evidence of an "intersection and interaction" (Molnar, 2014, p. 44) between new communications media and physical space. Rather than the physical city being deemed obsolete, the virtual and the physical represent "continuously intersecting social realities" (Molnar, 2014, p. 44). While the development of digital platforms has been criticised for generating new forms of control and surveillance (Mortensen, Neumayer, \& Poell, 2019), other work recognises the deliberative potential of digital and social media to enhance democratic participation, transparency and accountability. Schäfer (2015) talks of opportunities presented by a digital public sphere defined by open participation, the ability to discuss common concerns and discussions being more visible. The intersection and interaction between the digital and the physical are also evident in the sphere of contested politics, including protest movements. Arora (2015) makes the case for social network sites, as "centers of democracy and sites of protest" (p. 55). The social architectures of digital platforms can be powerful when they involve everyday social interactions that attract people who would otherwise be unlikely to join an advocacy group, or political party to express their discontent with local issues.

Bennett and Segerberg (2012, p. 743) coined the term connective action to reflect "digitally networked...engagement with politics as an expression of personal hopes, lifestyles and grievances." They identify the significance of digitally enabled action networks that allow for broader public engagement outside of more established party or movement concerns. They emphasise the importance of more personalised ideas and mechanisms, rather than social group identity, membership or ideology, utilising a wide range of social technologies to spread the word. Pond and Lewis (2019) build on this work, suggesting that connective action is a way to describe collective action "empowered by the 'logics' of social media" (p. 215) representing an "attempt to rethink the established logic of collective action for an age of hyper-mediated, personalised, political expression" (p. 213). It is argued that the architecture and codes embedded in social platforms enable collectivities to form at low cost and with (relatively) low risk for participants, which encourages the formation of these action networks. Pond and Lewis (2019) use the example of Twitter to highlight how its tools and practices, like retweeting and favouriting, encourage people to find those with similar political and personal interests, which form the basis of collective action.

Collective action logic has often failed because too few people agree on the public good that can be secured from working on a common cause, or do not make the contributions required to secure traction politically. Proponents argue that connective action frames can avoid this outcome because they are more accessible and individualised, eliminating barriers to entry and reducing costs, for both individuals and organisations. Wellestablished advocacy organisations are still important to connective action, engaging in what Bennett and Segerberg (2012) have called hybrid relations with other organisations to enable personal engagement through digital and social technologies. In this model, traditional organisational actors must avoid strong agendas and political brands in order to provide personal options in how people choose to participate and express themselves. As these publics share and personalise their content with trusted networks then the effects can be significant.

Despite the potential of digital platforms to facilitate connective action, there are legitimate concerns about equity of access, data privacy, increased surveillance, control and exclusion associated with the growth of these environments. Access to platforms does not guar- 
antee equitable participation or influence (Van Deursen, Helsper, Eynon, \& van Dijk, 2017). As Schäfer (2015) has suggested, even for those able to participate there is a danger that digital platforms encourage fragmentation into small communities of like-minded people, producing polarized views as opposed to producing greater diversity of opinion. Sunstein's (2007) work on online echo chambers and Pariser's (2011) consideration of filter bubbles further reinforce the need to be careful in overstating the democratic possibilities of digital platforms. The platform architectures used by organisations and individuals offer both possibilities and constraints, influencing how exchanges and connections take place (Poell, Rajagopalan, \& Kavada, 2018). Haggerty and Ericson (2000) express concern at the surveillant assemblage that social media platforms contribute towards as private corporations generate digital profiles of users that help predict future behaviours and tastes (Zuboff, 2019). On most social media platforms, global conglomerates make choices "about what can appear, how it is organised, how it is monetized, what can be removed and why, and what the technical architecture allows and prohibits" (Gillespie, 2010, p. 359). Finally, critics also suggest that the possibility of a digital public sphere is compromised on social platforms by the often emotional, confrontational and agnostic nature of online conversations, working against rational debate online (Schäfer, 2015).

However, while there are clearly many limitations to digital media platforms as a route to an idealized public sphere, there is a recognition that marginalized actors and silenced opinions can be made visible in the online space. While the material effects of Twitter campaigns may be unpredictable, ephemeral and never guaranteed they can also capture the attention of political leaders and produce greater democratic accountability. How effective this process can be is the focus of this study.

\section{The Uses and Management of Public Spaces: Privatization, Digitalisation and Festivalisation}

The idea that public spaces are collectively owned and shared environments, where diverse publics can gather and express themselves has been subject to considerable critique in recent years. Urban literatures suggest that experiences of public space vary from one category of individuals to the other, along dimensions including class (Mitchell, 2003), gender (Hubbard, 2001), race (Low, Taplin, \& Scheld, 2009) and age (Valentine, 1996).

However, accounting for the experiences of diverse populations in planning, designing and managing public spaces is impacted by powerful discourses which, at times, work against this agenda. As Smith (2016) suggests, urban public spaces are affected by three complementary threats. The first is securitization: This movement has increased in the past decades in the context of a global wave of neoliberal policies started in the United States in the 1980s and adopted afterwards in other contexts (Low \& Smith, 2006). Securitization affects public space as open spaces are closed off from the general public, with an increased use of militarized (and more and more technological) devices aiming to create an impression of control. This has been reinforced by a process of privatization: Instead of being owned by public institutions, public spaces have been reconstituted over the past two decades as private or quasi-private environments, managed in the context of public-private partnerships, and operating according to commercial logic. Each of these threats has contributed towards processes of commodification. In a context of fiscal tightening, the local state has been (re)imagined as an entrepreneurial entity, and public spaces have been reconstituted as assets that need to be exploited for economic return. Drawing on the case of public parks, Arora (2015) suggests that they now frequently represent and reflect "corporatized, commercialized, and semiprivatized space" (p. 63), generating growing concern amongst those people living near, using and caring for these spaces.

Accompanying these three threats is the emergence of digitalisation. Early analyses suggested that digitalisation would accelerate the decline of public spaces. It was argued that the growing prevalence of online exchanges would turn public spaces into a succession of insular private bubbles not related to physical proximity (Frith, 2012). However, another body of work highlights how technologies can also help to revive public spaces as an arena of meaningful debate. Far from evolving as separate entities, in the merging of digital and physical spaces the former becomes a place where local matters are debated (Papacharissi, 2002), while the latter turns into a 'hybrid space' influenced both by offline and online dynamics (de Souza e Silva, 2006). Digital platforms are now regularly utilised by local governments to foster civic engagement in the design process of public spaces (Gordon \& de Souza e Silva, 2011), but they have also been used by activists to generate collective actions which bypass official institutions. There is evidence that digital technologies can strengthen local involvement at the everyday political level: Neighbourhood groups, hyperlocal blogs or individual contributions on social networks are examples of ways through which concerned citizens now influence the debates on the future of urban public spaces (Gordon \& de Souza e Silva, 2011). However, questions remain as to who exerts the power in these digitally deliberative processes with Gordon and de Souza e Silva (2011, p. 111) highlighting that the efficient use of technology requires:

Being privy to the rules. It means knowing the best way to connect with neighbors and to consult politicians. It means not just having access to a communication tool, but knowing how best to use it for political and social gain.

The issue of festivals and events represents an appropriate context to explore the new relations between public space, privatization and digitalisation. Indeed, while 
squares, parks and streetscapes have historically been a prime location for events such as fairs, markets, or carnivals (Smith, 2016), these festive happenings have gained a new prominence in the eventful city (Richards \& Palmer, 2010) of the late capitalist period, where cultural and sporting occasions are increasingly tied to urban development strategies. While festivals and events can bring more visibility for marginalised groups in cities or generate new temporary social interactions, in their larger and more commercial forms they have been implicated as a representation of the crisis affecting urban public space. Critical commentators suggest that the normalisation of public spaces as event venues can contribute to the market orientation of urban environments, restricting access to spaces normally open to all or extending commercial logic by forcing attendees to pay for using them (Smith, 2018). Lately, the emergence of digital platforms has also led these criticisms to be expressed online: While digital platforms have been used by many festival and event organisers and sponsors to promote activities happening in public space, it has also often become a way through which a wider public can "enable the inversion of the power relationship between consumer and producer, opening up new avenues for the expression of protest and dissent" (McGillivray \& Frew, 2014, p. 2660).

In the remainder of this article, we explore how these criticisms have formalised offline and online in a city defined since 1949 by its internationally recognised festivals. While festivals and events have become significant cultural, social and economic assets to Edinburgh, and to Scotland's place in the world, the city's dependency towards them has produced in the last few years a set of urban controversies. Played out in both offline and online spaces, these debates emphasized the (over) use of public space as a central topic.

\section{Methodology}

Mortensen et al. (2019) suggest that contentious politics and social media materialities need to be studied through three axes: space, time and platforms. Spatially, they urge scholars to consider the physical locations of protests as well as the "social media platforms and people showing solidarity from afar through digital networks" (Mortensen et al., 2019, p. 4). They also suggest that it is important to consider time, including the accelerating practices associated with social media platforms. Finally, they propose a greater focus on "how social media platforms and activist practices shape one another" (Mortensen et al., 2019, p. 5) so that a greater understanding of contentious politics operating on different (social) media platforms can be secured. Wang and Chu (2019) also address the importance of online collective action as a "space where both formal and informal organisations use social media to engage with the public" (p. 394), and highlight Twitter as a suitable platform for both spreading information through broadcast but also to allow users to find and communicate with others with the same interests and form a collective and amplified voice. The benefits of using the Twitter platform for this type of community building and connective action arise from its immediacy in terms of mobile access, $4 \mathrm{G}$ signals and smartphones, its ease of use (in sharing images, texts and news articles) and its search functionalities and algorithms (Plunz et al., 2019).

It is important to acknowledge that Twitter is, at best, a semi-public space, given its ownership status and selective user profiles. Founded in 2006, Twitter is a microblogging platform developed in San Francisco. Now a globally recognised platform with 330 million active users (Clement, 2020), its $\$ 30$ bn profit is generated through advertisements and selling data to partners through APIs or crawlers. The majority of Twitter users are aged between 18 and 49 (Clement, 2020). While there is much debate on the issue, Kozinets (2020) suggests that Twitter data can be considered as public information posted on a public site, unless the tweet has been posted by a user with a private account.

Drawing on these considerations, we utilised a mixed methodological approach to explore online (via Twitter) and offline conversations pertaining to the urban controversies over festivals and urban public space in Edinburgh. Following Kozinets' (2020) netnography framework, we spent several months immersed in the Twitter data, informed by knowledge of the sector. We observed offline and online discussions on Twitter (including individual accounts), over the period from 1 June 2019 until 31 January 2020, focused on festivals and public space. These dates were chosen to highlight significant events taking place in Edinburgh over this period which had generated debate online about the use of urban public space, with a focus on the city's East and West Princes Street Gardens (Figure 1).

Publicly accessible Tweets were gathered and organised using the commercial social media monitoring tool, Brandwatch. Initial search terms included 'Edinburgh Summer Sessions,' 'Edinburgh Christmas Markets,' and 'Edinburgh Hogmanay,' though towards the end of our data collection period the hashtag \#CityforSale became significant and was included in our data set. We triangulated the Twitter data with mainstream news articles to better understand the actions or events that had triggered conversations online. Kozinets (2020) suggests the importance of seeking "lead users or lead situations," explaining that these are "users, whose present strong needs will become general" (p. 289). We checked the Twitter data for the inclusion of lead users-key social media influencers based on the frequency of their contributions, number of followers and impact of their tweets in terms of being shared with others. Finally, we also collected relevant local and national newspaper articles as these were often shared on Twitter to trigger reactions and start a conversation.

All tweets gathered around the search terms discussed (English language only, geolocation set to Scotland only) were saved into a search on the 


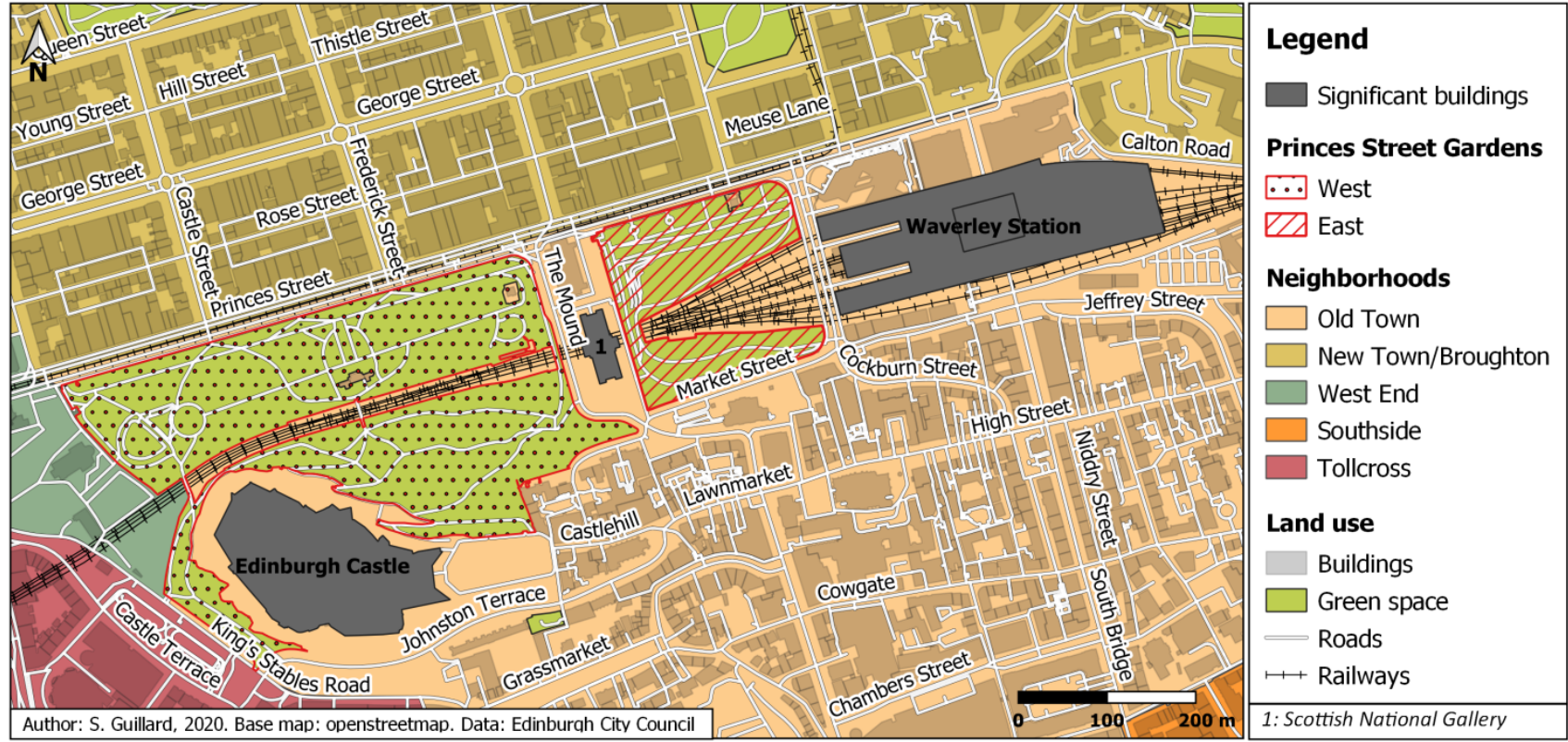

Figure 1. Map of Princes Street Gardens and surrounding areas. Source: Severin Guillard.

Brandwatch Platform. Our initial data collection gathered several thousand tweets. Further cleansing of the data was carried out using the functionalities of the Brandwatch platform to identify key themes and events, and to remove spam tweets or those posted by bots. Key themes and events were identified from the Twitter data and transferred into a CSV (excel) sheet to identify patterns of behaviour, numbers of retweets and conversations taking place around significant posts. We individually consulted the CSV Twitter data and returned to the original Twitter posts to gain more context around the posts where needed, collectively building the themes discussed in the next section of this article.

Although social media posts belong to the author of the post, the EU's General Data Protection Regulation confirm that if they are posted on social media platforms they can be used as publicly available data (DMA, 2019) to provide context or insight. In keeping with ethos of the General Data Protection Regulation, we chose to include example Twitter posts, being careful to ensure that individuals could not be easily identified. We removed Twitter handles to anonymise tweets from individual accounts (see also DMA, 2019; Duffy, Reid, \& Finch, 2020; Kozinets, 2020) to afford users a reasonable expectation of privacy. However, those users who were already public figures in their own right were not anonymised, as they often represent larger civil or commercial organisations relevant to the narratives of this case (e.g., local government officials).

To enhance the quality of data produced, Kozinets (2020) suggests that netnographic studies can be complemented by other data collection methods such as interviews and secondary news sources, to help researchers fully immerse themselves in the data, allow them to seek clarification and to understand the motivations and behaviours around participants' digital activities. We car- ried out semi-structured interviews with three key informants involved in initiating and mobilising debate on the use of public space for festivals and events in Edinburgh. These informants were the Chair of a long-standing and influential civic heritage organisation, the editor of a prominent hyperlocal media outlet operating in the city centre, and a former City of Edinburgh Council (CEC) employee who had experience in developing policy for the use and management of public space in the city.

Finally, while not residents of the city, we spent time there attending events and public meetings over the course of the study period and one author participated in the \#CityforSale event on invitation, given his work in the area over a number of years. In investigating a case of contentious politics, it is crucial that researchers immerse themselves in the research site, including observing the digital expressions of debate found online. In the following sections, we identify and discuss three key phases of the urban controversies, organised chronologically around events hosted in public spaces in Edinburgh in mid-late 2019 and early 2020.

\section{Controversy \#1: Summer Sessions}

East and West Princes Street Gardens, the site of much of the festival and event activity discussed in this article, represent iconic public spaces at the foot of Edinburgh Castle, an internationally renowned World Heritage Site and attraction. The CEC describes West Princes Street Gardens as: "One of the most cherished public green spaces in Scotland...by locals and visitors...one of the most beautiful and celebrated city-centre green spaces, offering a backdrop unparalleled anywhere in the world" (West Princes Street Garden Project, 2020).

Questions over who can and should be able to use these spaces for festival activity have come to the fore in 
Edinburgh in recent years, culminating in urban controversies materialising in the summer of 2019 and building until the early part of 2020. In June 2019, during a consultation on the redevelopment of the Ross Bandstand in West Princes Street Gardens, local conflict emerged over the appropriate classification of a major event, and confusion around the number and size of events that should be hosted there. One of Edinburgh's oldest civic heritage organisations challenged the development plans, with their Chair stating that while the bandstand was originally built to provide entertainment, "what has been notably stepped up in recent years...is the scale and frequency of events in the gardens" (personal communication).

Local concerns intensified with plans by Scottish music promoters, DF Concerts, to host their Summer Sessions music concerts over 11 days in August 2019, closing off a large area of West Princes Street Gardens around the Ross Bandstand to public access before, during and after the concerts. At this point civic heritage organisations, local community councils and (hyper) local media outlets became more vocal through traditional and social media to raise awareness about what they saw as leading the privatisation of public space in the city. An article in The Scotsman (a national newspaper in Scotland, based in Edinburgh) sparked Twitter activity that would continue throughout the summer and into the winter period. In the article titled "We Risk Losing Edinburgh's Princes Street Gardens as We Know Them Forever," the Chair of The Cockburn Association is quoted as saying that "Princes Street Gardens should be just that-gardens. We worry that the provision of a major 'world-leading' venue for gigs will see a creep to staging more large events" (Hague, 2019).

The Cockburn Association had been actively campaigning against the over-commercialisation of Edinburgh's civic heritage for years but their visibility increased with this foray into the media, accompanied by a growing following on their social media platforms ( 8,706 followers at the time of writing). In August 2019, another Scotsman article included comments from the promoter of the Summer Sessions concerts, Geoff Ellis, who expressed his concerns around attempts to block pop and rock concerts at the Ross bandstand in Edinburgh. Ellis suggested that "The Gardens are for everyone to enjoy, including music fans. To deny such joys is both selfish and elitist" (Ellis, 2019). However, despite this intervention, the issue of public space being compromised, or eroded, continued to gain traction, especially on Twitter. These concerns included that public parks could be closed to the public (including pavements), and the use of public space to host commercial events, as noted in these tweets:

I do want the Ross Bandstand kept for concerts. I don't want the Gardens stopped from being public parks. I don't want the pavement on Princes St blocked off to many users. (Cook, 2019)
Manifesto: Stop commercial exploitation of heritage sites \& green space. Demand quality, curated events sympathetic to venues \& sustainable. Reign in parasitic Fringe and Xmas race to the bottom. Make companies pay \#Edinburgh is living not \#FestivalCity \#CityCentreTransformation. (TesoDB, 2019)

The urban controversy accelerated further during the Summer Sessions concert programme itself with more Twitter activity and media articles commenting on the introduction of barriers within the West Princes Street Gardens, closing of public pathways, the erection of large sound curtains, and limited pavement access. From June to September 2019, 166 tweets alone mentioned either the curtains or barriers in West Princes Street Gardens, highlighting how this issue had translated into a personalised form of political expression. Twitter users shared images of the barriers, curtains and signage put in place to restrict access to the public. One tweet (Figure 2) showing an image of benches being closed off by fences leading to a narrower pathway was especially popular, retweeted 185 times with 66 comments. Local residents posted images of signage indicating no access to Princes Street Gardens, with one user arguing that this is "the nearest green space to my home, not a commercial venue" (retweeted 14 times, 16 August 2019; Harte, 2019a).

The Summer Sessions events and their fallout, played out on both mainstream and social media, fostering a growing sense that the local state was prioritising revenue generation over protecting citizen's access to civic public space. As the Chair of the established civic heritage organisation suggested:

Summer Sessions was probably a tipping point in it all because it was much more intrusive most notably physically by the screening along Princes Street....I think that together with other events it suggested that we were moving from a situation of a garden with an occasional event in, to an event space set in a garden. (Personal communication)

The sense that CEC was prioritising the exploitation of public space for revenue generation over its value for recreation, relaxation and recuperation was reinforced with the second major controversy-the installation of major event infrastructure in East Princes Street Gardens in November 2019 to host the annual Edinburgh Winter Festival and Markets.

\section{Controversy \#2: Underbelly and the Winter Festivals and Markets}

Since 2013, Underbelly, a commercial live event organisation, has been contracted by CEC to produce Edinburgh Christmas Markets (attracting over 2.6 million visitors in 2019) and Edinburgh Hogmanay (attracting 160,000 visitors). The Edinburgh Christmas Markets are held in East 
with Princes Street Gardens shut to the public and buses gridlocked all along the street, look what out helpful council are doing - it's gridlock on the pavements too

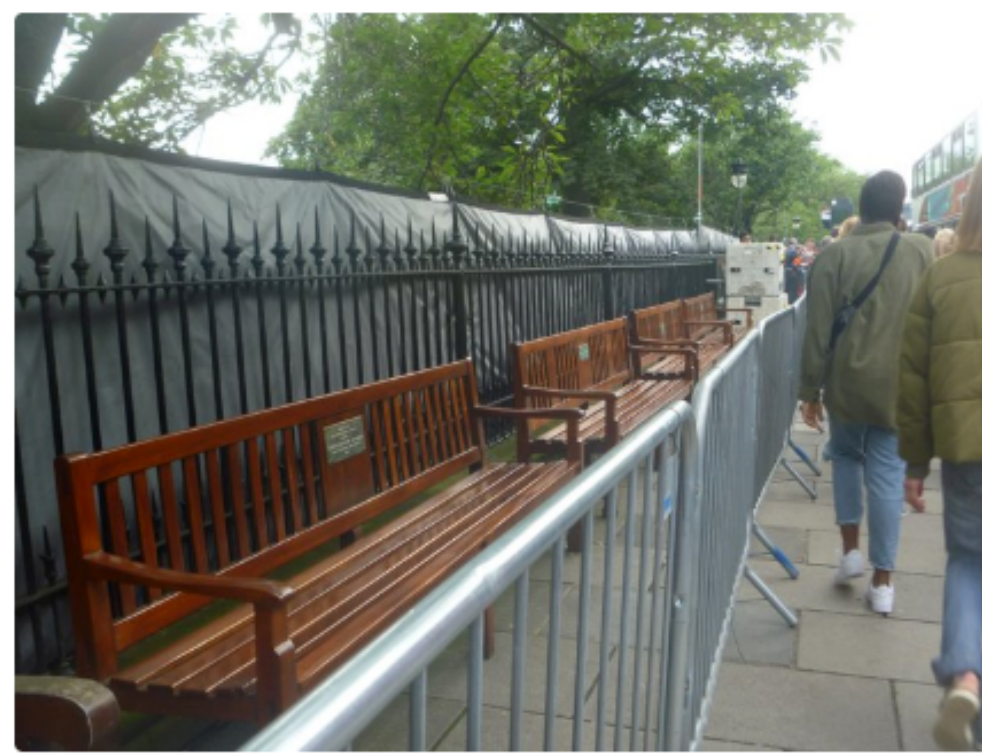

O 302 6:20 PM - Aug 8, 2019

Figure 2. Barriers and curtains overlooking West Princes Street Gardens. Source: Wilson (2019).

Princes Street Gardens, opening mid-November through to early January. Concerns about the damage caused by infrastructure built to host the Christmas Markets had been expressed online for the last two years, with Twitter users apportioning blame to Underbelly and CEC for damage to the ground conditions in East Princes Street Gardens and its trees and saplings. However, while these concerns were generating some traction on social media, it was the revelation that Underbelly had not secured planning permission for the built infrastructure required for the 2019 Edinburgh Christmas Markets that produced a veritable explosion of print media and social media activity which reignited debate about the prioritisation of revenue generation over the foregrounding of local democratic processes, including planning.

Along with several civic heritage organisations, the Citizen Network, old town and new town community councils and local (hyper) media outlets used social media to draw attention to the fact that the CEC was riding roughshod over normal democratic processes and prioritising the interests of commerce in its relationship with Underbelly. For example, a local activist shared images of the Christmas Markets being set up in October 2019 , despite a lack of planning permission, garnering 86 retweets and 96 likes (Figure 3 ).

Subsequently, the cyber commentary (Molnar, 2014) about Edinburgh on Twitter described it as being similar to Blackpool or Disneyworld, with the Christmas Markets commercialised rather than offering an experience reflective of the city's local culture and people. The online conversations were becoming increasingly politicised, as individual and group accounts began to coalesce around the notion that Edinburgh was selling out to commercial interests, in particular the demands of global tourism. The controversy over the Edinburgh Christmas Markets continued through November and into December 2019, incorporating the arrangements in place for Edinburgh's world-famous Hogmanay street party and celebrations which also started to generate greater critical scrutiny, especially on social media. Like the Christmas Markets, this event was promoted by Underbelly, as part of their contract with CEC. On Twitter, several images appeared showing areas of Princes Street Gardens blocked off for the Hogmanay celebrations, despite the events not taking place for a further two weeks. Figure 4 illustrates, showing a tweet from 15 December 2019, retweeted 91 times and with 167 likes.

Demonstrating how the debate extended beyond organised social groups, advocacy organisations and narrow political motives, one particularly significant thread on Twitter, started by a concerned member of the public consisted of 12 tweets posted on 22 December 2019, a week before the Hogmanay events were due to begin. The thread highlighted restrictions placed on local residents by Underbelly. Key tweets from the thread included: "This Hogmanay, Underbelly are making Edinburgh residents apply for permission to access their own homes. All residents will have to pass a police check before Underbelly decide to grant them permission to access their property" (Duncan, 2019; the opening tweet from the thread, retweeted 1,300 times, 1,200 likes and 229 comments, 22 December 2019). 
Despite no planning permission, Underbelly Ltd are still extending scaffolding, now the entire east-west length of East Princes Street Gardens. (Guard tried to stop picture taking from the higher section of the gardens still open.) Photo/6pm, 26 Oct.
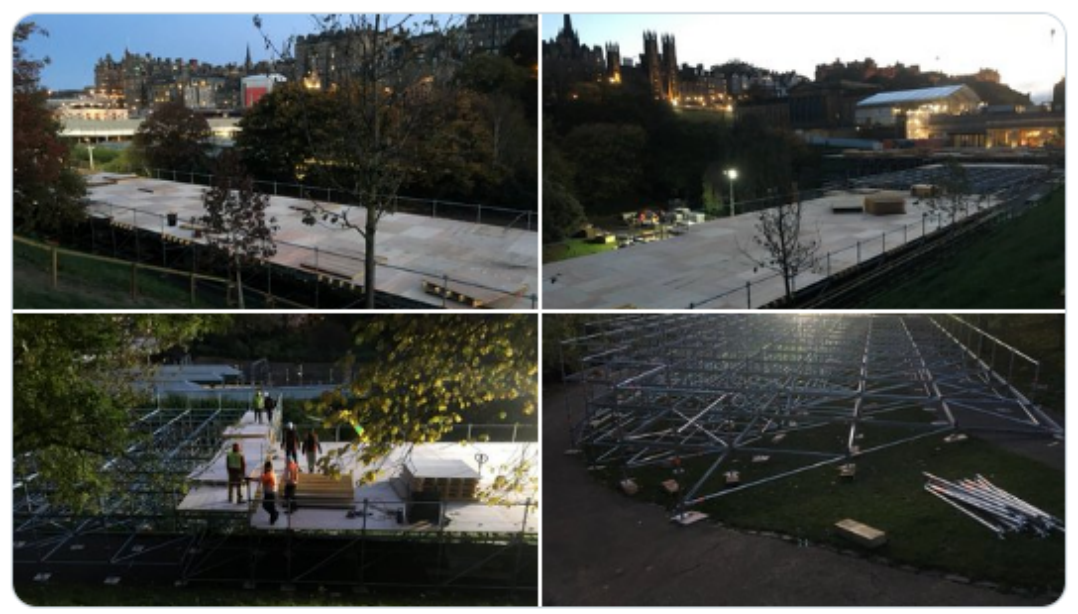

7:36 PM · Oct 26, 2019 · Twitter Web App

86 Retweets 96 Likes

Figure 3. Building the Edinburgh Christmas Markets. Source: Holledge (2019).

Isn't it depressing that we are weeks away from the Hogmanay event already the wretched udderbelly have blocked off most of the West Princes St Gardens (not satisfied by taking most of the East Gardens out of action for normal use). @EdinOldTownCC

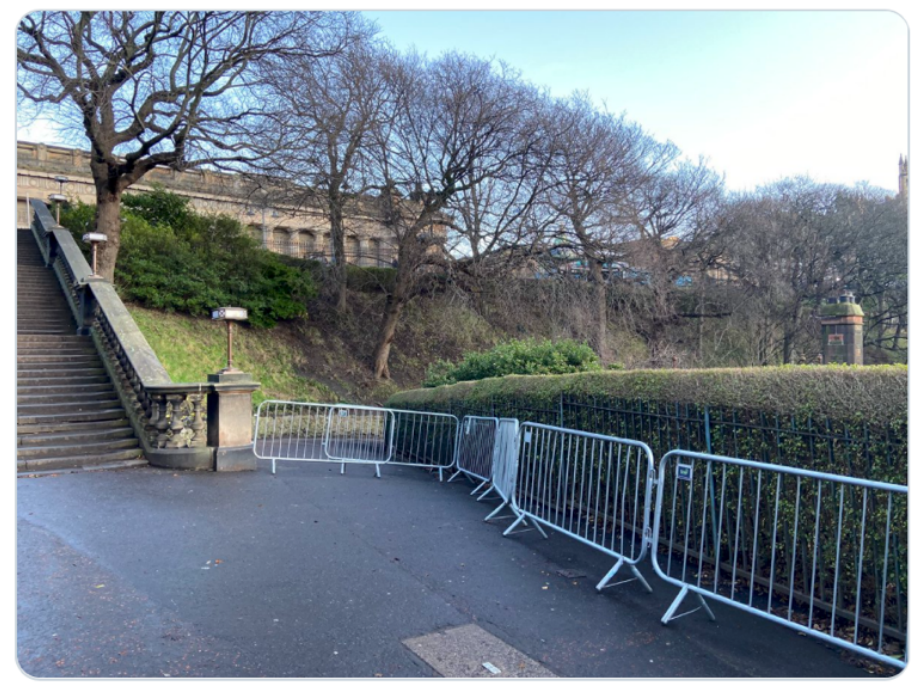

2:28 PM - Dec 15, $2019 \cdot$ Twitter for iPhone

91 Retweets 15 Quote Tweets 167 Likes

Figure 4. Closed Gardens for Hogmanay. Source: Harte (2019b). 
The author of the thread also included a response from the promoters:

RESPONSE FROM UNDERBELLY: "Access to homes is maintained at all times with no cost to businesses or residents, but security is ensured by the pass system." So, we should be grateful that residents don't have to pay to access their own homes? Is that it? (Duncan, 2019; retweeted 46 times and 315 likes, 22 December 2019)

The furore around the Edinburgh Christmas Markets and Hogmanay accelerated the volume and intensity of online activity, drawing in both local media and national media outlets at the end of 2019 and into early 2020. These outlets were full of stories about the negative impact of festivals and events hosted in the city's prime public space(s). Illustrating connective action in operation, much of the Twitter activity identified or tagged emerged from individuals' private accounts, albeit complemented by the tactical contributions of key advocacy and civil society organisations with a stake in the debate. Critical mainstream media coverage, locally and nationally, further emphasised the growing sense that Edinburgh had reached a tipping point in its prioritisation of (commercial) festivals and events held in valuable, and valued, public space:

Hogmanay fury as Edinburgh residents told to apply for access to their own homes (Brooks, 2019);

Petition demands resignation of Edinburgh council leader Adam McVey over Disneyfication of Capital (Matchett, 2019);

The hijacking of Edinburgh's Hogmanay (Heathcote, 2020);

Edinburgh City Council warned to stop chasing new tourists (Learmouth, 2020);

How Edinburgh has been bought and sold for Hogmanay gold (Small, 2020);

Edinburgh is selling its soul by greedily chasing tourists (Goring, 2020).

While the generation of online noise is an accepted feature of social media campaigning (Mortensen et al., 2019), there is evidence that the combination of old and new media activity produced material effects offline, with local political actors, including the CEC leadership, forced to respond and account for the failure of normal deliberative democratic processes. The business sector also felt the need to respond to criticism and promote the value of festivals and events for the city's economy. An article in the Scotsman in November 2019, “City centre chief accuses Edinburgh's Christmas market critics of jumping on a bandwagon" (Ferguson, 2019) sought to shift the narrative and project a more positive argument about the value of these events to the city. However, this intervention did little to quell the growing malcontent, which materialised in the third phase of this urban controversy.

\section{Controversy \#3: The City for Sale}

January 2020 represented the height of online and offline agitation about the impact of festivals and events on public space in Edinburgh, with increasing levels of engagement from the wider public compared to messages posted in around the Summer Sessions controversy. For example, an image of the damaged green space in East Princes Street Gardens, shared on January 13 2020, produced 452 retweets, 879 likes and over 50 comments. The comments mostly expressed shock and anger at the mess of the public space and the role of the Council and the promoters in allowing it to happen (Figure 5).

A petition demanding that Councillor Adam McVey, Leader of CEC, be removed from his post received over 2,400 signatures. The extent of online criticism coming the way of the Council led to a public response on Twitter from McVey, where he acknowledged the existence of "strong feelings" and the fact that "we have to listen to all residents and respond to meet the challenge," mentioning that the controversy is part of "a wider debate about how we manage size \& scale of festivals and tourism" (McVey, 2019). He also confirmed that a citywide conversation was about to be launched "to help shape future events" and that "we'll publish details shortly of how we'll engage with City to look afresh \& decide collectively what's best for our City, our residents \& our economy" (McVey, 2019).

While the intervention by the CEC sought to quieten concerned citizens, it did little to shift the public mood in the city. Testing that mood, The Cockburn Association decided to host a public meeting titled City for Sale? The Commodification of Edinburgh's Public Spaces on 29 January 2020. With 850 attendees and 629 tweets posted to the hashtag \#Cityforsale by 139 unique authors, this offline/online event demonstrated the importance of the issue to the city's residents. Examples of highly amplified tweets included:

Apparently, there's twice as many people at \#Cityforsale than have replied to Edinburgh CC tourism consultation. People in Edinburgh want to be heard, lengthy online consultations clearly aren't working. Adam McVey please try harder. (Heald, 2020; retweeted 34 times and 98 likes, 22 January 2020)

Large turnout for the Cockburn \#Cityforsale public summit. Residents' concerns are clear: commodification of our public space has gone too far and must be reviewed (Edinburgh World Heritage, 2020; retweeted 24 times and 70 likes, 22 January 2020) 


\title{
Dear Edinburgh Council
}

\author{
Did you really cut down trees and bushes so that \\ Underbelly could use the site and leave it like this?
}

\author{
Has no one told you this is the bloody capital of \\ Scotland, and its centre ought to be sacrosanct, or do \\ you not care?
}

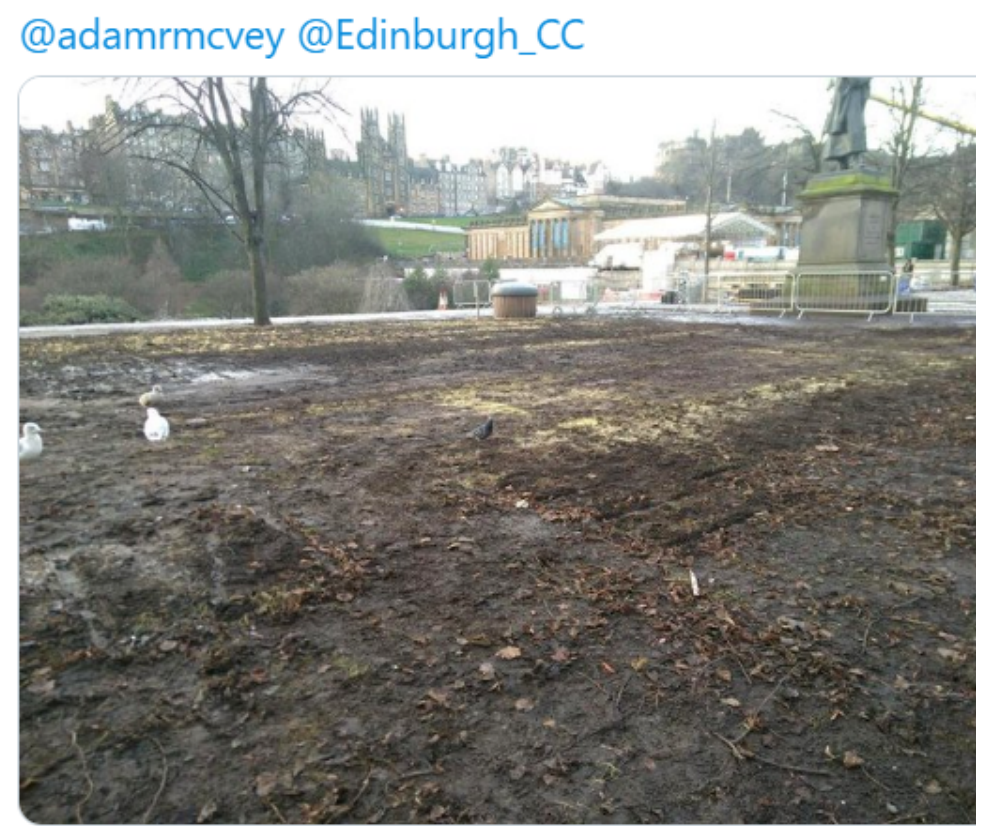

3:17 PM - Jan 13, 2020 - Twitter Web App

$\mathbf{4 5 2}$ Retweets $\mathbf{8 7 9}$ Likes

Figure 5. Aftermath of Christmas Markets. Source: Grouse Beater (2020).

The size and scale of the public's response to the urban controversies preceding the \#Cityforsale meeting reflected the momentum that had been generated, amplified by Twitter activity, since the middle of 2019. It also reflected the importance of both offline and online politics in mobilising support for contested political issues. In the final section of this article we return to debates about public space, festivalisation and digitalisation.

\section{Behind the (Virtual) Scene: The Mutual Influence of Offline and Online Politics}

The Edinburgh case described here reflects the presence of complex entanglements between mainstream media, local media, social media and offline politics. In this case, the interaction and intersection between the physical and the virtual were evident, with Twitter providing the platform for individuals and organisations to share striking visual images that powerfully illustrated concerns about the potential erosion of public space in Edinburgh. Schäfer $(2015$, p. 326) argues that in using social media, participants often:

Meander off topic, use unpleasant or abusive wording and ad hominem attacks, make claims not backed up by arguments or abstain from rational argumentation altogether, and use their social position in the given platform to delegitimize opposing views, or drive away opponents.

In the three controversies described here, there was certainly evidence of Twitter users using colourful language, direct attacks on local government officials and selective visual imagery to illustrate entrenched perspectives. However, it was also clear that Twitter represented a space where networks were established or strengthened, events and activities were structured and discontent was communicated, personally and institutionally. 
That is how connective action frames operate (Bennett $\&$ Segerberg, 2012). They are rarely unidirectional, involving one leader with a singular vision or objective. Instead, these frames are complex, unpredictable, and nuanced, producing temporary coalitions and affiliations that can hold opponents to account.

It was also evident that the urban controversies played out on Twitter and other platforms were partly a response to perceived democratic deficits in the decision-making processes for public space management in Edinburgh. Exploiting the powerful viral potential of connective action, temporary affiliations came together to raise awareness of problematic practices impacting on the current and future plans for the city's precious public space assets. If the public sphere were operating successfully, then deliberative processes would have enabled residents, civic heritage groups and other interested parties to participate in rational debate about the desired shape of public space, and of the role of festivals and events in the city. However, it was the very failure of that deliberative process, including concerns over relationships between private event operators and public bodies that initiated the desire to make visible and share information to connect a wider public to changes taking place in the city. As Jenkins, Ford, and Green (2013) famously suggested, newer media platforms enable the creation, sharing, reusing, and adaptation of content, generating spreadable media which can be difficult to control. Visual and textual content relating to the urban controversies in Edinburgh was spread over several months, generating the fervour that led to 850 people attending the public meeting. As the established civic heritage organisation suggested:

How we got so many people there was thanks largely to Underbelly. I don't think we could have done it without them, the Christmas market saga developed the way it did...we hit social media and it kinda took off and very quickly the tv had picked this up. I did stuff on BBC Reporting Scotland and the whole thing just mushroomed but mainly, I think, because of social media...each week that went by there was almost some new outrage. As the Christmas tree was sawn down, as the memorial benches were burnt, as the crib on the Royal Mile was removed, as the mud heaps appeared afterwards, you know, all of these things were like the fermenting agent that translated in the end to this ground swell of public concern. (Personal communication)

Building on Bennett and Segerberg's (2012) work, connective action frames need to be accessible and individualised, eliminating barriers to entry and reducing costs, for both individuals and organisations. Crucially, established organisations are still important but they need to avoid strong agendas and political brands so as not to deter individuals from participating. In the Edinburgh case, a range of civic heritage organisations coalesced with The Cockburn Association to raise awareness of the potential erosion of public space and the role of festivals and events in accelerating those processes. The Cockburn and its affiliates would have been less successful at animating the wider public had they not already secured credibility for carrying out their public space watchdog role for many years. Moreover, with a presence on Twitter since 2009, the organisation already had in excess of 6,000 followers before the start of the controversy. This prior online and offline presence was important in creating engagement from concerned citizens. Long standing credibility in the locale also contributed to media amplification of the campaign about Edinburgh's public spaces. Hyperlocal media organisations, in particular, played a significant role early on in amplifying the core message, further emphasising the logic of connective action and the importance of the hybrid model, where established voices align with personal interests via online platforms to form loose but powerful affiliations (Pond \& Lewis, 2019). As our hyperlocal media respondent suggested, mutual interest guided the involvement of multiple stakeholders in the campaign to protect public space in Edinburgh, though "we are not in any formalized, concerted plan of action" (personal communication).

Exploiting its distributed dynamic of exchange and more horizontal relationship between users (Pond \& Lewis, 2019), Twitter was an important platform in creating loose bridges between otherwise differentiated individuals and organisations. This case illustrates one of the strengths of connective action, whose "logic does not require strong organizational control or the symbolic construction of a united 'we"' (Bennett \& Segerberg, 2012, p. 748), as taking public action on social networks is seen first and foremost as an act of personal expression and recognition. Through the medium of Twitter in particular, various groups were able to cooperate in a complementary way without compromising their individual identities. While the presence of local advocacy organisations lent credibility to the cause, the local media was able to bring editorial independence and a direct channel to local residents, and creative storytellers like the Citizen Network (tagline, Reclaiming the City) produced powerful short films which reached out to bigger audiences to raise awareness of the need for change. This creative storytelling approach concurs with Gauntlett's (2011) view that social media users can adapt platforms for their own purposes, using them as spaces for creation, discussion and debate.

The Edinburgh case is an exemplar of how offline and online logics can merge and nourish each other. The City for Sale event was, ostensibly, an example of traditional offline collective action. However, in effect the Edinburgh Central Hall represented a hybrid space (de Souza e Silva, 2006) where the online debates were shared physically and virtually simultaneously. Its rootedness in a physical setting, with a large audience, strengthened the credibility of the online discussions-discussions that until then 
had been dismissed as online noise. Perhaps even more importantly, the urban controversies about public space described here illustrate that digitalisation processes can help protect and celebrate the value of public spaces. In Edinburgh, the visual documentation and sharing of images of barriers, fences, walls or curtains restricting access to public space reached an audience of interested and concerned citizens, often affected personally by the change to everyday lives. Exploiting the benefits of shareable media, this powerful imagery forced the local state and its commercial partners to respond and adapt its own practices of civic engagement to ensure a broader range of voices were heard in future public space design processes. Though played out on social media, a semipublic space, the Edinburgh controversies highlight the power of everyday creativity as a constituent element of connective action. It also shows that individuals and organisations are more than capable of understanding how to use digital media platforms successfully for political and social gain (Gordon \& de Souza e Silva, 2011).

\section{Conclusion}

At the outset, we posed a question about the relationship between online and offline politics in the context of hosting festivals and events in urban public space, and their effects. While it remains too early to assess the long-term impact of these urban controversies on the shape of Edinburgh's urban public spaces and the activities which take place within them, it is clear that a fertile online and offline public exists. When the political is personalised and people are able to align with an action frame, policy makers can be held to account and forced to adapt their practices in response to the demands of their citizens. In this article we have demonstrated that the digital sphere can play an important role in informing and influencing the production and regulation of urban public space. While previous analyses have shown how governments try to use digital platforms to encourage civic engagement from local residents, the Edinburgh case illustrates how other forms of digitalisation also allow citizens to bypass official institutions and contribute to debates about the future of public space. Weaknesses in digital forms of deliberation, especially the ubiquity of online consultations, creates a space for alternative practices that enable disaffected citizens to influence decision making over their urban environs. While connective action using social media leaves open questions of power, privacy and equity of access, this study shows that when established organisations capture the public mood both online and offline then meaningful social action can be initiated and sustained, at least in the short term.

In the specific case of debates about the festivalisation of public space in Edinburgh, we have shown how residents and concerned groups felt the need to move online to express dissatisfaction with how these spaces were being managed, programmed and regulated by the local state. For increased awareness and attention of injustices to be translated into sustained and effective political action, traditional organisational actors had to ensure that their strong agendas allowed personal options in how people participated and expressed themselves. The Edinburgh case shows that concerned citizens, sharing and personalising their content with their own networks heightened the effects of their action. Powerful user generated images can generate attention that, when amplified by local and national media outlets, and offline political activities, can produce change. While connective action is often subject to criticism for requiring less commitment from its participants, we suggest that if mobilised effectively, social platforms represent a powerful means of strengthening local democracy in the offline space.

\section{Acknowledgments}

The project, Festspace, has received funding from the HERA Public Spaces European Union's Horizon 2020 research and innovation programme under grant agreement 769478.

\section{Conflict of Interests}

The authors declare no conflict of interests.

\section{References}

Aelbrecht, P. (2019). New public spaces of circulation, consumption and recreation and their scope for informal social interaction and cohesion. In P. Aelbrecht \& Q. Stevens (Eds.), Public space design and social cohesion: An international comparison (pp. 199-219). London: Routledge.

Arora, P. (2015). Usurping public leisure space for protest: Social activism in the digital and material commons. Space and Culture, 18(1), 55-68.

Bennett, W. L., \& Segerberg, A. (2012). The logic of connective action: Digital media and the personalization of contentious politics. Information, Communication \& Society, 15(5), 739-768.

Brooks, L. (2019, December 26). Hogmanay fury as Edinburgh residents told to apply for access to their own homes. The Guardian. Retrieved from https://www.theguardian.com/uk-news/2019/dec/ 26/edinburgh-residents-restrictions-hogmanay

Clement, J. (2020). Twitter: Number of monetizable daily active users worldwide 2017-20. Statista. Retrieved from https://www.statista.com/statistics/970920/ monetizable-daily-active-twitter-users-worldwide

Cook, A. [AWCook0558]. (2019, August 21). I do want the Ross Bandstand kept for concerts. I don't want the Gardens stopped from being public parks. I don't want the pavement on Princes St blocked off to many users [Tweet]. Retrieved from https://twitter.com/ AWCook0558/status/1164187848200925184 
de Souza e Silva, A. (2006). From cyber to hybrid: Mobile technology as interfaces of hybrid spaces. Space and Culture, 9(30), 261-278.

DMA. (2019). Social media, GDPR and data. London: Data \& Marketing Association. Retrieved from https://dma.org.uk/uploads/misc/social-media,the-gdpr-and-data1.pdf

Duffy, K., Reid, E., \& Finch, J. (2020). Sold out? Reconfiguring consumer demand through the secondary digital ticket market. Consumption Markets \& Culture, 23(2), 174-194.

Duncan, A. [Angus_Duncan]. (2019, December 22). THREAD: This Hogmanay, Underbelly are making Edinburgh residents apply for permission to access their own homes. All residents will have to pass a police check before Underbelly decide to grant them permission to access their property [Tweet]. Retrieved from https://twitter.com/Angus_Duncan/ status/1208857248564436992

Edinburgh World Heritage. [EdinburghWH]. (2020, January 22). Large turnout for the Cockburn \#Cityforsale public summit. Residents' concerns are clear: commodification of our public space has gone too far and must be reviewed [Tweet]. Retrieved from https://twitter.com/EdinburghWH/status/ 1220078196479156224

Ellis, G. (2019, August 21). It's selfish and elitist to object to Summer Sessions concerts: Geoff Ellis. The Scotsman. Retrieved from https://www.scotsman. com/arts-and-culture/edinburgh-festivals/its-selfishand-elitist-object-summer-sessions-concerts-geoffellis-542410

Ferguson, B. (2019). City centre chief accuses Edinburgh's Christmas market critics of jumping on a bandwagon. The Scotsman. Retrieved from https:// www.scotsman.com/arts-and-culture/edinburghfestivals/city-centre-chief-accuses-edinburghschristmas-market-critics-jumping-bandwagon1282036

Frith, J. (2012). Splintered space: Hybrid spaces and differential mobility. Mobilities, 7(1), 131-149.

Gauntlett, D. (2011). Making is connecting: The social meaning of creativity, from DIY and knitting to Youtube and Web 2.0. London: Polity.

Gillespie, T. (2010). The politics of 'platforms.' New Media \& Society, 12, 347-364.

Gordon, E., \& de Souza e Silva, A. (2011). Net locality: Why location matters in a networked world. London: Wiley-Blackwell.

Goring, R. (2020, January 29). Edinburgh is selling its soul by greedily chasing tourists. The Herald. Retrieved from https://www.heraldscotland.com/ news/18195438.edinburgh-selling-soul-greedilychasing-tourists---rosemary-goring

Grouse Beater. [grouse_Beater]. (2020, January 13). Dear Edinburgh Council, Did you really cut down trees and bushes so that Underbelly could use the site and leave it like this [Tweet]. Retrieved from
https://twitter.com/Grouse_Beater/status/ 1216741044504682502

Haggerty, K. D., \& Ericson, R. V. (2000). The surveillant assemblage. British Journal of Sociology, 51(4), 605-622.

Hague, C. (2019, May 7). We risk losing Edinburgh's Princes Street Gardens as we know them forever: Cliff Hague. The Scotsman. Retrieved from https:// www.scotsman.com/heritage-and-retro/heritage/ we-risk-losing-edinburghs-princes-street-gardenswe-know-them-forever-cliff-hague-547158

Harte, S. [Sjharte]. (2019a, August 16). The nearest green space to my home, not a commercial venue [Tweet]. Retrieved from https://twitter.com/sjharte/status/ 1162377721038671872

Harte, S. [Sjharte]. (2019b, December 15). Isn't it depressing that we are weeks away from the Hogmanay event already the wretched udderbelly have blocked off [Tweet]. Retrieved from https://twitter. com/sjharte/status/1206219580647051264

Heald, A. [andyheald]. (2020, January 22). Apparently there's twice as many people at \#Cityforsale than have replied to Edinburgh CC tourism consultation. People in Edinburgh want to be heard, lengthy online consultations clearly aren't working. Adam McVey please try harder [Tweet]. Retrieved from https://twitter.com/andyheald/status/12200884109 68395778

Heathcote, E. (2020, January 3). The hijacking of Edinburgh's Hogmanay. Financial Times. Retrieved from https://www.ft.com/content/b887760a-2be111ea-bc77-65e4aa615551

Holledge, S. [Holledge]. (2019, October 26). Despite no planning permission, Underbelly Ltd are still extended scaffolding, now the entire east-west length of East Princes Street Gardens [Tweet]. Retrieved from https://twitter.com/Holledge/status/120036964725 5740416

Hubbard, P. (2001). Sex zones: Intimacy, citizenship and public space. Sexualities, 4(1), 51-71.

Jamieson, K. (2014). Edinburgh: The festival gaze and its boundaries. Space \& Culture, 7(1), 64-75.

Jenkins, H., Ford, S., \& Green, J. (2013). Spreadable media: Creating value and meaning in a networked culture. New York, NY: New York University Press.

Kozinets, R. V. (2020). Netnography: The essential guide to social media research (3rd ed.). London: SAGE.

Learmouth, A. (2020, January 3). Edinburgh City Council warned to stop chasing new tourists. The National. Retrieved from https://www.thenational. scot/news/18134678.edinburgh-city-councilwarned-stop-chasing-new-tourists

Low, S., \& Smith, N. (2006). The politics of public space. New York, NY: Routledge.

Low, S., Taplin, D., \& Scheld, S. (2009). Rethinking urban parks: Public space and cultural diversity. Austin, TX: University of Texas Press.

Matchett, C. (2019, December 31). Petition demands 
resignation of Edinburgh council leader Adam McVey over Disneyfication of Capital. Edinburgh Evening News. Retrieved from https://www. edinburghnews.scotsman.com/news/politics/ council/petition-demands-resignation-edinburghcouncil-leader-adam-mcvey-over-disneyficationcapital-1351592

McGillivray, D., \& Frew, M. (2014). From fan parks to live sites: Mega events and the territorialisation of urban space. Urban Studies, 52(14), 2649-2663.

McVey, A. [adammcvey]. (2019, December 30). 1.Xmas/Hogmanay- earlier this year I confirmed a Citywide conversation in 2020 to help shape future events \& meet our aspirations \& concerns. There are understandably strong feelings \& we have to listen to all residents \& respond to meet the challenge [Tweet]. Retrieved from https://twitter.com/ adamrmcvey/status/1211584712738836480

Mitchell, D. (2003). The right to the city: Social justice and the fight for public space. New York, NY: Guilford Press.

Molnar, V. (2014). Reframing public space through digital mobilization: Flash mobs and contemporary urban youth culture. Space \& Culture, 17(1), 43-58.

Mortensen, M., Neumayer, C., \& Poell, T. (2019). Social media materialities and protest. London: Routledge.

Papacharissi, Z. (2002). The virtual sphere: The internet as a public sphere. New Media \& Society, 4(1), 9-27.

Pariser, E. (2011). The filter bubble: What the internet is hiding from you. New York, NY: The Penguin Group.

Plunz, R. A., Zhou, Y., Vintimilla, M. I. C., Mckeown, K., Yu, T., Uguccioni, L., \& Sutto, M. P. (2019). Twitter sentiment in New York City parks as measure of well-being. Landscape and Urban Planning, 189, 235-246.

Poell, T., Rajagopalan, S., \& Kavada, A. (2018). Publicness on platforms: tracing the mutual articulation of platform architectures and user practices. In Z. Papacharissi (Ed.), A networked self and platforms, stories, connections (pp. 43-58). New York, NY: Routledge.

Pond, P., \& Lewis, J. (2019). Riots and Twitter: Connective politics, social media and framing discourses in the digital public sphere. Information, Communication \& Society, 22(2), 213-231.

Rabari, C., \& Storper, M. (2015). The digital skin of cities: Urban theory and research in the age of the sensored and metered city, ubiquitous computing and big data. Cambridge Journal of Regions, Economy and Society, 8(1), 27-42.
Richards, G., \& Palmer, R. (2010). Eventful cities. Oxford: Butterworth-Heinemann.

Schäfer, M. S. S. (2015). Digital public sphere. In G. Mazzoleni (Ed.), The international encyclopedia of political communication (pp. 322-328). London: Wiley Blackwell.

Small, M. (2020, January 5). How Edinburgh has been bought and sold for Hogmanay gold. The National. Retrieved from https://www.thenational.scot/news/ 18138100.edinburgh-bought-sold-hogmanay-gold

Smith, A. (2016). Events in the city: Using public spaces as event venues. Abingdon: Routledge.

Smith, A. (2018). Paying for parks: Ticketed events and the commercialisation of public space. Leisure Studies, 37(5), 533-546.

Sunstein, C. R. (2007). Republic 2.0. Princeton, NJ: Princeton University Press.

TesoDB. [TesoDB]. (2019, June 26). Manifesto: Stop commercial exploitation of heritage sites \& green space. Demand quality, curated events sympathetic to venues \& sustainable. Reign in parasitic Fringe and $X$ mas race to the bottom. Make companies pay \#Edinburgh is living not \#FestivalCity \#CityCentreTransformation [Tweet]. Retrieved from https://twitter.com/ tesodb/status/1143589506072961024

Valentine, G. (1996). Children should be seen and not heard: The production and transgression of adults' public space. Urban Geography, 17(3), 205-220.

Van Deursen, A., Helsper, E., Eynon, R., \& van Dijk, J. A. G. M. (2017). The compoundness and sequentiality of digital inequality. International Journal of Communication, 11, 452-473.

Wang, R., \& Chu, K. H. (2019). Networked publics and the organizing of collective action on Twitter: Examining the \#Freebassel campaign. Convergence, 25(3), 393-408. vWest Princes Street Garden Project. (2020). Consultation hub. City of Edinburgh Council. Retrieved from https://consultationhub.edinburgh. gov.uk/bi/west-princes-street-gardens-project

Wilson, J. [craftygreeenpoet]. (2019, August 8). With Princes Street Gardens shut to the public and buses gridlocked all along the street, look what our helpful council are doing - it's gridlock on the pavements too [Tweet]. Retrieved from https://twitter.com/ craftygreenpoet/status/1159514769814110211

Zuboff, S. (2019). The age of surveillance capital: The fight for the future at the new frontier of power. London: Profile Books.

\section{About the Authors}

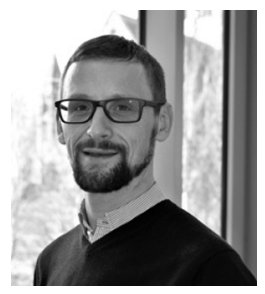

David McGillivray holds a Chair in Event and Digital Cultures at University of the West of Scotland. His research interests focus on two main areas. First, a critical reading of the contemporary significance of events and festivals as mechanisms for the achievement of wider economic, social and cultural externalities. Second, he focuses on the affordances of digital culture, especially related to understandings of digital citizenship, participation and the role of everyday digital media platforms and practices. 


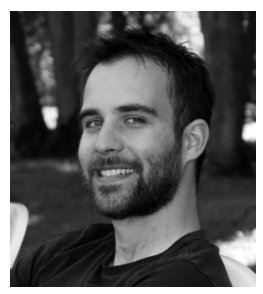

Severin Guillard is a Researcher in Geography and Urban Studies. His research interests focus on cultural practices and power relations in cities, and he explores these issues through various topics (rap music, cultural policies, events, and tourism) and countries (France, United States, United Kingdom). He is currently a Postdoctoral Research Fellow at the University of the West of Scotland on the Festspace HERA project (Festivals, Events and Inclusive Public Space in Europe).

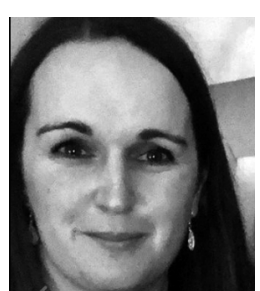

Emma Reid is a Lecturer in Marketing at the University of the West of Scotland where she teaches on the undergraduate and postgraduate marketing programmes. Emma's areas of research focus around a broad range of marketing topics and she has published in the areas of digitalisation, netnography and market studies. Prior to working in academia, Emma worked for a range of industries including social listening agencies, marketing and the construction sector. 